NASA Technical Memorandum 81490

DYNAMIC RESPONSE TO ROTATING-SEAT RUNOUT IN NON-CONTACTING FACE SEALS

\title{
I. Etsion
}

Lewis Research Center

Cleveland, Ohio

April 1980 
DYNAMIC RESPONSE TO ROTATING-SEAT RUNOUT IN NON-CONTACTING FACE SEALS

by I. Etsion

Lewis Research Center

\section{ABSTRACT}

The dynamic response of a flexibly-mounted ring to runout of the rotating seat in mechanical face seal is analyzed assuming small perturbations. It is found that tracking ability of the stator depends only on its dynamic characteristics and operating conditions and is not affected by the amount of runout. Three different modes of dynamic response are shown and the condition for parallel tracking is presented. 
NOMENCLATURE

$A_{i} \quad$ coefficients, see eqs. (46) and (47), $i=1,2,3,4$

$a_{i}$ coefficients, see eqs. (32) to (34), $i=1,2,3$

C seal clearance along center line

$\mathrm{C}_{\mathrm{O}} \quad$ equilibrium clearance

F force

$\overline{\mathrm{F}}$ dimensionless force, $\mathrm{F} / \mathrm{Sr}_{\mathrm{O}}^{2}$

h film thickness

I stator moment of inertia about diameter

$\overline{\mathrm{I}}$ dimensionless moment of inertia, $\mathrm{I} \omega^{2} / \mathrm{Sr}_{\mathrm{o}}^{3}$

$\mathrm{K} \quad$ spring constant per unit of circumferential length, $K^{*} / 2 \pi \mathbf{r}_{\mathrm{sp}}$

$\overline{\mathrm{K}}$ dimensionless spring constant, $\mathrm{K} / \mathrm{S}$

K* $\quad$ spring constant

M moment

$\overline{\mathrm{M}} \quad$ dimensionless moment, $\mathrm{M} / \mathrm{Sr}_{\mathrm{O}}^{3}$

m stator mass

$\overline{\mathrm{m}}$ dimensionless mass, $\mathrm{m} \omega^{2} \mathrm{C}_{\mathrm{o}} / \mathrm{Sr}_{\mathrm{o}}^{2}$

p pressure

$R$ dimensionless radius, $r / r_{0}$

r radial coordinate

$\mathbf{r}_{\mathrm{g}} \quad$ stator radius of gyration

$\mathrm{r}_{\mathrm{sp}} \quad$ springs radial location 


\begin{tabular}{|c|c|}
\hline $\mathrm{S}$ & seal parameter, $\mu \omega\left(1-R_{i}\right)^{2}\left(r_{o} / C_{o}\right)^{3}$ \\
\hline $\mathrm{t}$ & time \\
\hline $\mathrm{X}, \mathrm{Y}, \mathrm{Z}$ & axes of inertial reference \\
\hline$x_{r}, y_{r}, z_{r}$ & axes of reference fixed to rotor \\
\hline $\mathrm{x}_{\mathrm{s}}, \mathrm{y}_{\mathrm{s}}, \mathrm{z}_{\mathrm{s}}$ & axes of reference attached to stator \\
\hline $\mathbf{Z}$ & stator axial displacement \\
\hline $\bar{Z}$ & dimensionless displacement $\mathrm{Z} / \mathrm{C}_{\mathrm{O}}$ \\
\hline$\alpha$ & stator angular displacement \\
\hline$\gamma_{\mathrm{r}}$ & rotor runout \\
\hline$\gamma_{\mathrm{S}}$ & stator nutation \\
\hline$\gamma^{*}$ & relative tilt between stator and rotor \\
\hline$\epsilon$ & tilt parameter, $\gamma^{*} \mathrm{r}_{\mathrm{o}} / \mathrm{C}$ \\
\hline$\theta$ & angular coordinate in reference $1,2,3$ \\
\hline$\lambda$ & exponent of homogeneous solution \\
\hline$\mu$ & viscosity \\
\hline$\tau$ & dimensionless time, $\omega \mathrm{t}$ \\
\hline$\phi$ & angular coordinate in reference $\mathrm{X}, \mathrm{Y}, \mathrm{Z}$ \\
\hline$\phi^{*}$ & angular location of plane of maximum film thickness \\
\hline$\psi$ & angular location of plane $z_{S}, y_{S}$ in reference $X, Y, Z$ \\
\hline$\omega$ & shaft angular ve'ocity \\
\hline
\end{tabular}


Subscripts:

$\begin{array}{ll}1,2,3 & \text { axes of reference } 1,2,3 \\ \text { cr } & \text { critical } \\ \text { f } & \text { fluid } \\ \mathrm{m} & \text { inner radius } \\ \mathrm{o} & \text { mean radius } \\ \mathrm{r} & \text { outer radius } \\ \mathrm{s} & \text { rotor } \\ \mathrm{sp} & \text { stator } \\ \mathrm{X}, \mathrm{Y}, \mathrm{Z} & \text { inertial reference axes } \\ \mathrm{x}_{\mathrm{S}}, \mathrm{y}_{\mathrm{S}}, \mathrm{z}_{\mathrm{S}} & \text { axes of reference } \mathrm{x}_{\mathrm{s}}, \mathrm{y}_{\mathrm{s}}, \mathrm{z}_{\mathrm{S}}\end{array}$

INTRODUCTION

Runout of the rotating seat in high speed radial face seals is almost an inevitable factor which seals designers have to face. Considering the extremely small gap (of the order of a few micrometers) that separates the faces in a noncontacting face seal (fig. 1), even the slightest runout can cause clearance variation of the order of the designed separation. Moreover, since the misaligned seat is rotating, the effect is of a cyclic nature and can excite vibrations of the flexibly-mounted seal ring.

Determination of the conditions for dynamic tracking of the misaligned rotating seat has been attempted by several investigators $[1,2,3]$. However, these analyses do not cover the complete range of dynamic response, and, in some cases, they are incomplete, treating only one degree of freedom of the flexibly-mounted ring. 
The dynamic behavior of a stationary, flexibly-mounted ring facing an aligned rotating-seat was analyzed in a previous paper [4]. It was found that when the ring is slightly disturbed from its equilibrium parallel position, one of three modes can prevail. The initial disturbance can decay, or increase in time, or it can stay constant while the ring is wobbling at half the shaft frequency. The half-frequency wobble is still a matter of controversy among seal researchers [5], and although it has been observed experimentally [6,7], a synchronous motion of the ring seems to be predominant.

It is the objective of this paper to extend the analysis of reference [4] to the more general case where the rotating seat has a certain amount of axial runout, and to find the dynamic response of the flexibly-mounted ring under such conditions.

\section{SEAL MODEL AND COORDINATE SYSTEMS}

The seal model and various coordinate systems are shown in figure 2 . The reference $\mathrm{x}_{\mathrm{r}}, \mathrm{y}_{\mathrm{r}}, \mathrm{z}_{\mathrm{r}}$ is fixed to the rotor which is rotating at a constant angular velocity $\omega$ about the $Z$ axis of an inertial reference $X, Y, Z$. The runout of the rotor is represented by the constant angle $\gamma_{\mathrm{r}}$ between axes $\mathrm{z}_{\mathrm{r}}$ and $\mathrm{Z}$. Axis $y_{r}$ is always pointing to the point of minimum distance between the rotor and plane XY. The stator has three degrees of freedom, it can move axially along the $\mathrm{Z}$ axis and rotate about the $\mathrm{X}$ and $\mathrm{Y}$ axes. The reference $\mathrm{x}_{\mathrm{S}}, \mathrm{y}_{\mathrm{S}}, \mathrm{z}_{\mathrm{S}}$ is attached to the stator plane but is free to rotate in it, so that axis $y_{S}$ is always pointing to the point of maximum distance between the stator and plane $\mathrm{XY}$. The resu ting motion of reference $\mathrm{x}_{\mathrm{S}}, \mathrm{y}_{\mathrm{S}}, \mathrm{z}_{\mathrm{S}}$ is a combination of nutation $\gamma_{\mathrm{S}}$ and precession $\psi$.

Consider a plane $\mathrm{O}_{S} \mathrm{O}_{\mathrm{r}} \mathrm{AB}$ (fig. 2) at an angle $\phi$ from the plane $\mathrm{XZ}$. The distance between points $A$ and $B$, that are located radially at distance $r$ from axis $\mathrm{Z}$, is the local film thickness and is given by

$\mathrm{h}=\mathrm{C}+\gamma_{\mathrm{S}} \mathrm{r} \cos (\phi-\psi)-\gamma_{\mathrm{r}} \mathrm{r} \cos (\phi-\omega t)$ 
where $\mathrm{C}$ is the separation $\mathrm{O}_{\mathrm{S}} \mathrm{O}_{\mathbf{r}}$ along the seal centerline, $\psi$ is the angle between planes $z_{S} x_{s}$ and $z X$, and $\omega t$ is the angle between planes $z_{r} x_{r}$ and $\mathrm{ZX}$, corresponding to the precessions of references $x_{s}, y_{s}, z_{s}$ and $x_{r}, y_{r}, z_{r}$, respectively.

The angle $\phi^{*}$ corresponding to the plane of maximum film thickness can be found from equation (1) by setting $\mathrm{dh} / \mathrm{d} \phi=0$, hence

$\gamma_{\mathrm{S}} \sin \left(\phi^{*}-\psi\right)=\gamma_{\mathrm{r}} \sin \left(\phi^{*}-\omega \mathrm{t}\right)$

or

$\operatorname{tg} \phi^{*}=\frac{\gamma_{\mathrm{S}} \sin \psi-\gamma_{\mathrm{r}} \sin \omega \mathrm{t}}{\gamma_{\mathrm{S}} \cos \psi-\gamma_{\mathrm{r}} \cos \omega \mathrm{t}}$

The relative tilt between stator and rotor can now be defined by an angle $\gamma^{*}$, measured in the plane of maximum film thickness, between the axes $z_{s}$ and $z_{r}$. Figure 3 shows the relative position of stator and rotor which can be described by the relative position between a new reference 1,2,3 and the reference $x_{r}, y_{r}, z_{r}$. The reference $1,2,3$ is free to rotate about the $z_{r}$ axis so that axis 2 always points to the point of maximum film thickness and the plane 12 is always within the plane of the stator. The film thickness $h$ can be described by the relative tilt $\gamma^{*}$ and the angular coordinate $\theta$ measured from the plane of maximum clearance to the plane $\mathrm{O}_{\mathrm{S}} \mathrm{O}_{\mathbf{r}} \mathrm{AB}$. Hence,

$\mathrm{h}=\mathrm{C}+\gamma^{*} \mathrm{r} \cos \theta$

where

$\theta=\phi-\phi^{*}$

Equating (1) and (3) and using (4) we have

$\gamma^{*} \cos \left(\phi-\phi^{*}\right)=\gamma_{\mathrm{S}} \cos (\phi-\psi)-\gamma_{\mathrm{r}} \cos (\phi-\omega t)$

Differentiating (5) with respect to $\phi$ gives

$\gamma^{*} \sin \left(\phi-\phi^{*}\right)=\gamma_{\mathrm{S}} \sin (\phi-\psi)-\gamma_{\mathrm{r}} \sin (\phi-\omega \mathrm{t})$ 
Squaring equations (5) and (6) and adding yields

$\gamma^{*}=\gamma_{\mathrm{S}}^{2}+\gamma_{\mathrm{r}}^{2}-2 \gamma_{\mathrm{S}} \gamma_{\mathrm{r}} \cos (\psi-\omega \mathrm{t})$

Equations (5) and (6) are true for any $\phi$, hence,

$\gamma^{*} \cos \phi^{*}=\gamma_{\mathrm{S}} \cos \psi-\gamma_{\mathrm{r}} \cos \omega \mathrm{t}$

$\gamma^{*} \sin \phi^{*}=\gamma_{\mathrm{S}} \sin \psi-\gamma_{\mathrm{r}} \sin \omega \mathrm{t}$

SYSTEMS OF FORCES AND MOMENTS

For small angles $\gamma_{\mathrm{r}}$ and $\gamma_{\mathrm{S}}$, which is the practice in seals, the equations of motion of the stator in the inertial reference $X, Y, Z$ are [4] .

$$
\begin{aligned}
& \mathrm{m} \ddot{\mathrm{Z}}=\Sigma \mathrm{F}_{\mathrm{Z}} \\
& \mathrm{I} \ddot{\alpha}_{\mathrm{X}}=\Sigma \mathrm{M}_{\mathrm{X}} \\
& \mathrm{I} \ddot{\alpha}_{\mathrm{Y}}=\Sigma \mathrm{M}_{\mathrm{Y}}
\end{aligned}
$$

where $I$ is the stator moment of inertia about its diameter; and $\Sigma \mathrm{F}, \Sigma \mathrm{M}$ are the proper forces and moments acting on the stator. These forces and moments are contributed by the fluid film between stator and rotor, and by the spring support on the back of the stator (fig. 1).

Fluid film force and moments

The fluid film force and moments are more readily obtained in the reference $1,2,3$ and then transformed into the reference $X, Y, Z$. These force and moments can be found from integration of the fluid film pressure which, in turn, is found from a solution of the Reynolds equation

$\frac{\partial}{\partial \mathrm{r}}\left(\mathrm{h}^{3} \frac{\partial \mathrm{p}}{\partial \mathrm{r}}\right)=6 \mu\left(\omega \frac{\partial \mathrm{h}}{\partial \theta}+2 \frac{\partial \mathrm{h}}{\partial \mathrm{t}}\right)$

The boundary conditions of (13) are

$\mathrm{p}=\mathrm{p}_{\mathrm{i}}$ at $\mathrm{r}=\mathrm{r}_{\mathrm{i}}$ 
$\mathrm{p}=\mathrm{p}_{\mathrm{o}}$ at $\mathrm{r}=\mathrm{r}_{\mathrm{o}}$

The film thickness, $h$, is given by equation (3) from which, by using equation (4), we find

$\frac{\partial \mathrm{h}}{\partial \theta}=-\gamma^{*} \mathrm{r}_{\mathrm{m}} \sin \theta$

$\frac{\partial \mathrm{h}}{\partial \mathrm{t}}=\dot{\mathrm{z}}+\dot{\gamma}^{*} \mathrm{r}_{\mathrm{m}} \cos \theta+\gamma^{*} \dot{\phi}^{*} \mathrm{r}_{\mathrm{m}} \sin \theta$

Equations (13), (14), and (15) are based on the narrow seal approximation where both circumferential pressure gradient and seal curvature are neglected [8] .

Defining a relative tilt parameter $\epsilon$ in the form

$\epsilon=\frac{\gamma^{*} r_{0}}{C}$

and assuming small perturbations, that is, $\epsilon^{2} \ll 1$, the approach taken in [4] can be followed which results in the linear expressions

$F_{3}=-2 \pi \mu\left(\frac{r_{o}}{C_{o}}\right)^{3} r_{o} R_{m}\left(1-R_{i}\right)^{3} C_{0} \dot{\bar{Z}}$

$\mathrm{M}_{1}=-\frac{\pi}{4}\left(\frac{\mathrm{r}_{\mathrm{o}}}{\mathrm{C}_{\mathrm{o}}}\right) \mathrm{r}_{\mathrm{o}}^{3} \mathrm{R}_{\mathrm{m}}^{2}\left(1-\mathrm{R}_{\mathrm{i}}\right)^{2}\left(\mathrm{p}_{\mathrm{i}}-\mathrm{p}_{\mathrm{o}}\right) \gamma^{*}-\pi \mu\left(\frac{\mathrm{r}_{\mathrm{o}}}{\mathrm{C}_{\mathrm{o}}}\right)^{3} \mathrm{r}_{\mathrm{o}}^{3} \mathrm{R}_{\mathrm{m}}^{3}\left(1-\mathrm{R}_{\mathrm{i}}\right)^{3} \dot{\gamma}^{*}$

$\mathrm{M}_{2}=\pi \mu\left(\frac{\mathrm{r}_{\mathrm{o}}}{\mathrm{C}_{\mathrm{o}}}\right)^{3} \mathrm{R}_{\mathrm{m}}^{3}\left(1-\mathrm{R}_{\mathrm{i}}\right)^{3}\left(\frac{\omega}{2}-\dot{\phi}^{*}\right) \gamma^{*}$

where $C_{0}$ is an initial separation and $\bar{Z}$ is a dimensionless axial translation $\bar{Z}=\mathrm{Z} / \mathrm{C}_{\mathrm{o}}$, hence 
$\mathrm{C}=\mathrm{C}_{\mathrm{o}}(1+\overline{\mathrm{Z}})$

Figure 4 shows the relative position of reference 1,2,3 and the inertial reference $\mathrm{X}, \mathrm{Y}, \mathrm{Z}$. From this description and the assumption of very small tilt $\gamma_{\mathbf{S}}$ we have

$$
\left(\mathrm{F}_{\mathrm{f}}\right)_{\mathrm{Z}}=\mathrm{F}_{3}
$$

$\left(M_{f}\right)_{X}=M_{1} \cos \phi^{*}-M_{2} \sin \phi^{*}$

$$
\left(\mathrm{M}_{\mathrm{f}}\right)_{\mathrm{Y}}=\mathrm{M}_{1} \sin \phi^{*}+\mathrm{M}_{2} \cos \phi^{*}
$$

Flexible support contribution

In calculating the support forces only the springs are considered while coulomb friction of the secondary seal is neglected. Such a model properly describes metal bellows seals, however, its stability limit can be used as an upper limit for cases where friction in the secondary seal is present. This is because the adritional friction damping increases the seals stability, provided the friction is not too high and causes stator hangup.

Assuming the stator is so designed that the spring loading is balanced at $\mathrm{Z}=0, \gamma_{\mathrm{S}}=0$. If the spring constant per unit of circumferential length is $\mathrm{K}$, and the springs are located at $r=r_{s p}$, the support reactions to a translation $Z$ and tilt $\gamma_{S}$ are (fig. 2)

$\left(\mathrm{F}_{\mathrm{Sp}}\right)_{\mathrm{Z}}=-2 \pi \mathrm{Kr}_{\mathrm{o}} \mathrm{R}_{\mathrm{sp}} \mathrm{C}_{\mathrm{o}} \overline{\mathrm{Z}}$

and

$$
\left(\mathrm{M}_{\mathrm{sp}}\right)_{\mathrm{x}_{\mathrm{s}}}=-\pi \mathrm{Kr}_{\mathrm{o}}^{3} \mathrm{R}_{\mathrm{sp}}^{3} \gamma_{\mathrm{s}}
$$


which in the interial reference is resolved into

$\left(\mathrm{M}_{\mathrm{sp}}\right)_{\mathrm{X}}=\left(\mathrm{M}_{\mathrm{sp}}\right)_{\mathrm{x}_{\mathrm{S}}} \cos \psi$

and

$\left(M_{s p}\right)_{Y}=\left(M_{s p}\right)_{X_{S}} \sin \psi$

EQUATIONS OF MOTION

Defining a seal parameter $S$ in the form

$S=\mu \omega\left(\frac{r_{0}}{C_{o}}\right)^{3}\left(1-R_{i}\right)^{2}$

where $\mathrm{S}$ has dimensions of force per unit area, the forces and moments can be normalized by

$\overline{\mathrm{F}}=\frac{\mathrm{F}}{\mathrm{Sr}_{\mathrm{o}}^{2}}$

$\overline{\mathrm{M}}=\frac{\mathrm{M}}{\mathrm{Sr}_{\mathrm{o}}^{3}}$

The spring rate per unit circumferential length is normalized by

$\overline{\mathrm{K}}=\frac{\mathrm{K}}{\mathrm{S}}$

Summing up all the forces and moments in the inertial reference $\mathrm{X}, \mathrm{Y}, \mathrm{Z}$ by using equations (17) through (28), we have

$\Sigma \overline{\mathrm{F}}_{\mathrm{Z}}=-\frac{2}{\mathrm{R}_{\mathrm{m}}^{2}} \frac{\mathrm{C}_{\mathrm{o}}}{\mathrm{r}_{\mathrm{o}}}\left[\mathrm{a}_{2}\left(\frac{\mathrm{R}_{\mathrm{m}}}{\mathrm{R}_{\mathrm{sp}}}\right)^{2} \overline{\mathrm{z}}+\frac{2 \mathrm{a}_{3}}{\omega} \dot{\mathrm{z}}\right]$ 
$\Sigma \overline{\mathrm{M}}_{\mathrm{X}}=-\mathrm{a}_{1} \gamma^{*} \cos \phi^{*}-\frac{2 \mathrm{a}_{3}}{\omega}\left[\dot{\gamma}^{*} \cos \phi^{*}+\left(\frac{\omega}{2}-\dot{\phi}^{*}\right) \gamma^{*} \sin \phi^{*}\right]-\mathrm{a}_{2} \gamma_{\mathrm{s}} \cos \psi$

$\Sigma \overline{\mathrm{M}}_{\mathrm{Y}}=-\mathrm{a}_{1} \gamma^{*} \sin \phi^{*}-\frac{2 \mathrm{a}_{3}}{\omega}\left[\dot{\gamma}^{*} \sin \phi^{*}-\left(\frac{\omega}{2}-\dot{\phi}^{*}\right) \gamma^{*} \cos \phi^{*}\right]-\mathrm{a}_{2} \gamma_{\mathrm{S}} \sin \psi$

where the dimensionless coefficients $a_{1}, a_{2}, a_{3}$ are

$\mathrm{a}_{1}=\frac{\pi \mathrm{R}_{\mathrm{m}}^{2}}{4} \frac{\mathrm{p}_{\mathrm{i}}-\mathrm{p}_{\mathrm{o}}}{\mathrm{s}} \frac{\mathrm{r}_{\mathrm{o}}}{\mathrm{C}_{\mathrm{o}}}\left(1-\mathrm{R}_{\mathrm{i}}\right)^{2}$

$a_{2}=\pi R_{s p}^{3} \bar{K}$

$a_{3}=\frac{\pi}{2} R_{m}^{3}\left(1-R_{i}\right)$

Since the nutation angle of the stator $\gamma_{\mathrm{S}}$ and its rotation angles $\alpha_{\mathrm{X}}$ and $\alpha_{\mathrm{Y}}$ about the $\mathrm{X}$ and $\mathrm{Y}$ axes, respectively, are very small, they can be treated as veciors. Hence (see fig. 2)

$\alpha_{\mathrm{X}}=\gamma_{\mathrm{S}} \cos \psi$

$\alpha_{\mathrm{Y}}=\gamma_{\mathrm{S}} \sin \psi$

From equations (8), (9), (35), and (36) we have

$\gamma^{*} \cos \phi^{*}=\alpha_{\mathrm{X}}-\gamma_{\mathrm{r}} \cos \omega \mathrm{t}$

$\gamma^{*} \sin \phi^{*}=\alpha_{\mathrm{Y}}-\gamma_{\mathrm{r}} \sin \omega t$

and the time derivatives are

$\dot{\gamma}^{*} \cos \phi^{*}-\dot{\phi}^{*} \gamma^{*} \sin \phi^{*}=\dot{\alpha}_{\mathrm{X}}+\omega \gamma_{\mathrm{r}} \sin \omega \mathrm{t}$ 
$\dot{\gamma}^{*} \sin \phi^{*}+\dot{\phi}^{*} \gamma^{*} \cos \phi^{*}=\dot{\alpha}_{\mathrm{Y}}-\omega \gamma \mathrm{r} \cos \omega t$

Substituting equations (35) through (40) in equations (30) and (31); using a dimensionless time $\tau=\omega \mathrm{t}$ for the derivatives $\dot{\overline{\mathrm{Z}}}, \ddot{\overline{\mathrm{Z}}}, \dot{\alpha}, \ddot{\alpha}, \dot{\gamma}$, and $\dot{\phi}$; and normalizing equations (10) through (12) we finally have

$\overline{\mathrm{m}} \ddot{\overline{\mathrm{Z}}}+\frac{4}{\mathrm{R}_{\mathrm{m}}^{2}} \frac{\mathrm{C}_{\mathrm{o}}}{\mathrm{r}_{\mathrm{o}}} \mathrm{a}_{3} \dot{\overline{\mathrm{Z}}}+\frac{2}{\mathrm{R}_{\mathrm{m}}^{2}} \frac{\mathrm{C}_{\mathrm{o}}}{\mathrm{r}_{\mathrm{o}}} \mathrm{a}_{2}\left(\frac{\mathrm{R}_{\mathrm{m}}}{\mathrm{R}_{\mathrm{sp}}}\right)^{2} \overline{\mathrm{Z}}=0$

$\overline{\mathrm{I}} \dot{\alpha}_{\mathrm{X}}+2 \mathrm{a}_{3} \dot{\alpha}_{\mathrm{X}}+\left(\mathrm{a}_{1}+\mathrm{a}_{2}\right) \alpha_{\mathrm{X}}+\mathrm{a}_{3} \alpha_{\mathrm{Y}}=\gamma_{\mathrm{r}}\left(\mathrm{a}_{1} \cos \omega \mathrm{t}-\mathrm{a}_{3} \sin \omega \mathrm{t}\right)$

$\overline{\mathrm{I}} \ddot{\alpha}_{\mathrm{Y}}+2 \mathrm{a}_{3} \dot{\alpha}_{\mathrm{Y}}+\left(\mathrm{a}_{1}+\mathrm{a}_{2}\right) \alpha_{\mathrm{Y}}-\mathrm{a}_{3} \alpha_{\mathrm{X}}=\gamma_{\mathrm{r}}\left(\mathrm{a}_{1} \sin \omega \mathrm{t}+\mathrm{a}_{3} \cos \omega \mathrm{t}\right)$

Equations (41), (42), and (43) are the dimensionless equations of motion of the stator in its three degrees of freedom. When there is no runout, that is, $\gamma_{r}=0$, these equations become identical to the equations of motion obtained in reference [4] as expected. Note again that the time derivatives $\ddot{\bar{z}}, \dot{\bar{z}}, \ddot{\alpha}$, and $\dot{\alpha}$ in equations (41) through (43) are with respect to a dimensionless time $\tau$ where

$\tau=\omega \mathrm{t}$

\section{RESULTS AND DISCUSSION}

From the equations of motion (41) through (43) it is clear that for small perturbations the stator motion in the axial degree of freedom is uncoupled with the two rotations. Moreover, the solution of (41) is independent of the runout, $\gamma_{r}$, and is therefore identical to the solution in reference [4] for $\gamma_{\mathbf{r}}=0$. Hence, as was found in reference [4] the stator is always stable in its axial degree of freedom, and any small disturbance from the equilibrium separation $\mathrm{C}_{\mathrm{O}}$ will decay in time. However, in order to avoid underdamping that 
results in unnecessary oscillations of the stator, a proper combination of the stator mass $\mathrm{m}$ and spring constant $\mathrm{K}^{*}$ should be selected. From equation (41) the condition for critical damping, and hence fastest decay of any axial disturbance, is

$4 \overline{\mathrm{m}} \frac{2}{\mathrm{R}_{\mathrm{m}}^{2}} \frac{\mathrm{C}_{\mathrm{o}}}{\mathrm{r}_{\mathrm{o}}} \mathrm{a}_{2}\left(\frac{\mathrm{R}_{\mathrm{m}}}{\mathrm{R}_{\mathrm{sp}}}\right)^{2}=\left(\frac{4}{\mathrm{R}_{\mathrm{m}}^{2}} \frac{\mathrm{C}_{\mathrm{o}}}{\mathrm{r}_{\mathrm{o}}} \mathrm{a}_{3}\right)^{2}$

which, by equations (33), and (34), and the definition of $\overline{\mathrm{m}}$ results in

$\left(\mathrm{mK}^{*}\right)_{\mathrm{cr}}=\left[\pi \mu \mathrm{r}_{\mathrm{m}}\left(\frac{\mathrm{r}_{\mathrm{o}}}{\mathrm{C}_{\mathrm{o}}}\right)^{3}\left(1-\mathrm{R}_{\mathrm{i}}\right)^{3}\right]^{2}$

Any combination of $\left(\mathrm{mK}^{*}\right)>\left(\mathrm{mK}^{*}\right)_{\mathrm{cr}}$ results in underdamping and should be avoided. Any combination $\left(\mathrm{mK}^{*}\right)<\left(\mathrm{mK}^{*}\right) \mathrm{cr}$ results in overdamping and may be acceptable. However, for fastest decay of axial disturbance $\mathrm{mK}^{*}=\left(\mathrm{mK}^{*}\right)_{\mathrm{c}_{i}}$ will be the best choice.

The homogeneous solution of equations (42) and (43) is also identical to that in reference [4] for the case $\gamma_{\mathbf{r}}=0$. Hence, the angular stability criterion is the same as in the absence of rotor runout. The runout $\gamma_{r}$ is merely a forcing function; thus, it affects only the particular solution of the angular equations of motion. The particular solution for the angles $\alpha_{\mathrm{X}}$ and $\alpha_{\mathrm{Y}}$ can be sought in the form

$$
\begin{aligned}
& \alpha_{X}=A_{1} \cos \omega t+A_{2} \sin \omega t \\
& \alpha_{Y}=A_{3} \cos \omega t+A_{4} \sin \omega t
\end{aligned}
$$

Substituting equations (45) and (46) into equations (42 and (43) and solving separately for the coefficients of $\sin \omega t$ and $\cos \omega t$ gives 


$$
\begin{aligned}
& A_{1}=A_{4}=\gamma_{\mathrm{r}} \frac{a_{3}^{2}+\left(a_{1}+a_{2}-\bar{I}\right) a_{1}}{a_{3}^{2}+\left(a_{1}+a_{2}-\bar{I}^{2}\right.} \\
& A_{2}=-A_{3}=\gamma_{r} \frac{a_{1} a_{3}-\left(a_{1}+a_{2}-\bar{I}\right) a_{3}}{a_{3}^{2}+\left(a_{1}+a_{2}-\bar{I}\right)^{2}}
\end{aligned}
$$

Thus, the particular solution for $\alpha_{\mathrm{X}}$ and $\alpha_{\mathrm{Y}}$ is

$\alpha_{X}=A_{1} \cos \omega t+A_{2} \sin \omega t$

$\alpha_{Y}=A_{1} \sin \omega t-A_{2} \cos \omega t$

From equations (49) and (50) it is clear that this solution yields

$\alpha_{\mathrm{X}}^{2}+\alpha_{\mathrm{Y}}^{2}=A_{1}^{2}+A_{2}^{2}$

and, hence, by equations (35) and (36) the contribution of the particular solution to the stator tilt, $\gamma_{\mathrm{S}}$, is

$\gamma_{s}=\left(A_{1}^{2}+A_{2}^{2}\right)^{1 / 2}$

Substituting equations (47) and (48) in (51) we find

$\gamma_{\mathrm{s}}=\gamma_{\mathrm{r}}\left[\frac{\mathrm{a}_{1}^{2}+\mathrm{a}_{3}^{2}}{\mathrm{a}_{3}^{2}+\left(\mathrm{a}_{1}+\mathrm{a}_{2}-\overline{\mathrm{I}}\right)^{2}}\right]^{1 / 2}$

Figure 5 is a graphical representation of the stator angular motion contributed by the particular solution of the angular equations of motion. The complete motion is a superposition of the particular and homogeneous solutions. The homogeneous solution has the form 
$\alpha_{\mathrm{X}}=\alpha_{\mathrm{Xo}} \mathrm{e}^{\lambda \tau}$

$\alpha_{\mathrm{Y}}=\alpha_{\mathrm{Yo}} \mathrm{e}^{\lambda \tau}$

where $\alpha_{\mathrm{Xo}_{0}}, \alpha_{\mathrm{Y}_{0}}$ is an initial disturbance. In reference [4] it was found that three modes of response to the disturbance $\alpha_{\mathrm{Xo}}, \alpha_{\mathrm{Yo}}$ are possible depending on the shaft speed $\omega$. If $\omega$ is less than a critical speed $\omega_{\text {cr }}$, then the initial disturbance $\alpha_{\mathrm{Xo}}, \alpha_{\mathrm{Yo}}$ decays in time. Hence, for $\omega<\omega_{\mathrm{cr}}$ the homogeneous contribution disappears after a while and the stator motion is described by the particular solution (eqs. (46) through (49) and fig. 5). If $\omega>\omega_{\mathrm{cr}}$ the initial disturbance increases in time and the seal may fail due to stator rotor touchdown. At the critical speed, $\omega=\omega_{\mathrm{cr}}$, the homogeneous solution becomes an oscillatory motion with a constant amplitude and at a frequency which is half the shaft speed. The critical speed, $\omega_{\mathrm{cr}}$, at which this half frequency wobble occurs was found in [4] from the condition

$\overline{\mathrm{I}}=4\left(\mathrm{a}_{2}+\mathrm{a}_{1}\right)$

which by equations (32), (33), and the definition of $\bar{I}$ results in

$\omega_{\mathrm{cr}}^{2}=\frac{\pi \mathrm{r}_{\mathrm{o}}^{3} \mathrm{R}_{\mathrm{m}}^{2}}{\mathrm{I}}\left[4 \mathrm{~K}\left(\frac{\mathrm{ri}_{\mathrm{sp}}}{\mathrm{R}_{\mathrm{m}}}\right)^{2} \mathrm{R}_{\mathrm{sp}}+\frac{\mathrm{r}_{\mathrm{o}}}{\mathrm{C}_{\mathrm{o}}}\left(1-\mathrm{R}_{\mathrm{i}}\right)^{2}\left(\mathrm{p}_{\mathrm{i}}-\mathrm{p}_{\mathrm{o}}\right)\right]$

For a circular-ring stator the moment of inertia about a diameter is

$\mathrm{I}=\frac{\mathrm{m}}{2} \mathrm{r}_{\mathrm{g}}^{2}$

where $r_{g}$ is the stator radius of gyration. Using equation (54), equation (53) can be rearranged in the form 


$$
\left(\frac{\mathrm{r}_{\mathrm{g}}}{\mathrm{r}_{\mathrm{sp}}}\right)^{2}\left(\frac{\mathrm{m} \omega^{2}}{\mathrm{~K}^{*}}\right)_{\mathrm{cr}}=4+2 \pi\left(1-\mathrm{R}_{\mathrm{i}}\right)^{2} \frac{\left(\mathrm{p}_{\mathrm{i}}-\mathrm{p}_{\mathrm{o}}\right) \mathrm{r}_{\mathrm{o}}}{\mathrm{K}^{*} \frac{\mathrm{C}_{\mathrm{o}}}{\mathrm{r}_{\mathrm{o}}}}\left(\frac{\mathrm{r}_{\mathrm{m}}}{\mathrm{r}_{\mathrm{sp}}}\right)^{2}
$$

Figure 6 presents stability limits based on equation (55) for seals of various ratios $R_{i}=r_{i} / r_{0}$. If the seal operates in the stable regime the stator will track the rotor in a synchronous mode (see eqs. (49( and (50)) and with a constant amplitude $\gamma_{\mathrm{S}}$ related to the runout $\gamma_{\mathrm{r}}$ by equation (52). At conditions of critical stability, half-frequency wobble is superimposed on the basic synchronous tracking. When the seal operates in the unstable regime tracking becomes impossible and failure occurs.

The synchronous tracking in the stable operation regime is not necessarily in phase with the runout. From figure 5 we see that the phase angle $\omega t-\psi$ is given by

$\cos (\omega t-\psi)=\frac{A_{1}}{\gamma_{S}}$

Hence, by equations (47) and (52)

$$
\cos (\omega t-\psi)=\frac{a_{3}^{2}+\left(a_{1}+a_{2}-\bar{I}\right) a_{1}}{\left(a_{1}^{2}+a_{3}^{2}\right)^{1 / 2}\left[a_{3}^{2}+\left(a_{1}+a_{2}-\bar{I}\right)^{2}\right]^{1 / 2}}
$$

Equations (52) and (56) give the amplitude $\gamma_{S}$ of the tracking stator and its phase angle $(\omega t-\psi)$, respectively, for a given seal geometry, spring constant, and operation conditions.

For minimum leakage it is important that the stator remains parallel to the rotor all the time. This requires $\gamma_{\mathrm{S}}=\gamma_{\mathrm{r}}, \psi=\omega \mathrm{t}$ (see fig. 2). From equation (56) the condition for $\psi=\omega t$ is 
$\mathrm{a}_{2}=\overline{\mathrm{I}}$

From equation (52) we see that condition (57) also fulfills the requirement $\gamma_{\mathrm{S}}=\gamma_{\mathrm{r}}$. Hence, the condition for parallel tracking is by (57) and (33), and the definition of $\overline{\mathrm{I}}$

$\mathrm{I} \omega^{2}=\pi \mathrm{r}_{\mathrm{sp}}^{3} \mathrm{~K}$

Substituting equations (54) in (58), the condition for parallel tracking becomes $\left(\frac{r_{g}}{r_{s p}}\right)^{2} \frac{m \omega^{2}}{K^{*}}=1$

The preceding analysis is based on the assumption of small perturbations, $\epsilon^{2} \ll 1$, which enables the linearization of the equations of motion. It is also assumed that the fluid film in the sealing gap is complete and does not cavitate. These assumptions permit analytical treatment of the complex problem of seals dynamics. In many applications where the runout is very small and the pressure differential is sufficient to suppress cavitation the above mentioned assumptions are very close to reality. Hence, the present results may be used as a tool for better understanding and design of non-contacting mechanical face seals. In particular, stability maps similar to these in figure 6 are useful with the additional conditions for parallel tracking represented by equation (59), and the critical damping given by equation (44).

It should also be noted that the present analysis deals with a flat stator that has very little static stability when the high pressure is on the outer diameter [9]. In these cases it would be benefitial to machine the stator with a certain amount of coning [10] to increase its static stability. The coning also helps in obtaining the desired equilibrium clearance $\mathrm{C}_{0}$. Except for altering the stability maps, coning will not change the basic nature of the dynamic response. 
This will still depend on the regime of the seal's operation. That is, in the stable regime synchronous tracking at some constant amplitude; in the unstable regime failure due to inability to track; and at the transition between these two regimes, half frequency wobble superimposed on the basic synchronous tracking. Indeed all these three modes of dynamic response were observed experimentally [7], verifying qualitatively the present theory.

A question often brought up among seals researchers and designers is how much runout can be tolerated before the stator loses its capability to track? The results of this work show that tracking ability of the stator is not affected by the amount of rotor runout but depends on the dynamic characteristics of the stator, the pressure differential, and the shaft speed. The runout itself is merely the amplitude of a forcing function and hence, does not affect the stability of the system. A word of caution should, however, be added at this point. Although the amount of runout does not affect the tracking ability of the stator it does affect its tilt $\gamma_{\mathrm{s}}$ and phase angle $\omega \mathrm{t}-\psi$. Hence, the amount of runout affects the relative tilt $\gamma^{*}$ and, therefore, the minimum film thickness between rotor and stator (see fig. 3). Thus, a situation may exist where the stator steadily tracks the rotor runout but the minimum film thickness becomes dangerously small, resulting eventually in seal failure. From equation (3) we see that the minimum film thickness, corresponding to $r=r_{0}$ and $\theta=\pi$, is

$\mathrm{h}_{\mathrm{min}}=\mathrm{C}-\gamma^{*} \mathrm{r}_{\mathrm{o}}$

Hence, when $\gamma^{*} \mathrm{r}_{\mathrm{o}} / \mathrm{C}$ approaches unity, $\mathrm{h}_{\mathrm{min}}$ approaches zero. A situation like this cannot be handled by the present analysis which is based on the assumption of small perturbation $\epsilon^{2} \ll 1$ and, therefore, will require a treatment of the more general nonlinear equations of motion. Some idea on the effect of the runout $\gamma_{\mathbf{r}}$ on the minimum film thickness can, however, be obtained from the present results. Consider equations (7), (52), and (56) we find 
$\gamma^{*}=\gamma_{\mathrm{r}} \frac{\left(\mathrm{a}_{2}-\overline{\mathrm{I}}\right)}{\left[\mathrm{a}_{3}^{2}+\left(\mathrm{a}_{1}+\mathrm{a}_{2}-\overline{\mathrm{I}}\right)^{2}\right]^{1 / 2}}$

From equation (61) we see again that the condition for parallel tracking, $\gamma^{*}=0$, is met when $a_{2}=\bar{I}$. in any other case $a_{2} \neq I$, after ensuring steady tracking (operation in the stable regime, see fig. 6) and critical damping, one can decide on a maximum permissible relative tilt $\gamma^{*}$ and use equation (61) to calculate the amount of runout $\gamma_{\mathrm{r}}$ that will be damaging.

It is also worthwhile noting that the presence of friction in stators having secondary seal $O$ ring and antirotation locks may prevent parallel tracking at all. In such seals dynamic instability can become a lesser problem (because of the additional damping) compared with the possibility of excessive relative tilt $\gamma^{*}$ caused by rotor runout.

\section{CONCLUDING REMARKS}

The dynamic response of a flexibly-mounted stator to runout of the rotating seat in radial face seals is analyzed. It is found that successful tracking is not affected by the amount of runout but rather by the nature of stator dynamic characteristics. Three different modes of dynamic response are possible. If the seal operates in a stable regime, synchronous tracking at constant ampl:tude prevails. In the unstable operating regime tracking is impossible, resulting in face contact due to angular instability. At the transition between these two regimes half frequency wobble is superimposed on the basic synchronous tracking. A condition for parallel tracking was found which is important for minimum leakage. It is also shown that the amount of runout, although not affecting the dynamic response of the system, may be responsible under non-parallel tracking conditions to seal failure due to an excessive relative tilt between stator and rotor.

The analysis is based on certain simplifying assumptions but nevertheless provides a good insight into the dynamic behavior of non-contacting face seals. 


\section{ACKNOWLEDGEMENT}

The research reported in this paper was performed while the author held a NRC-NASA research associateship at NASA Lewis Research Center, Cleveland, Ohio.

\section{REFERENCES}

1. Ludwig, L. P.; and Allen, G. P.: Face Seal Lubrication. II. - Theory of Response to Angular Misalignment. NASA TN D-8102, 1976.

2. Kupperman, David S.: Dynamic Tracking of Noncontacting Face Seals. ASLE Trans., vol. 18, no. 4, Oct. 1975, pp. 306-311.

3. Metcalfe, R.: Dynamic Tracking of Angular Misalignment in Liquid Lubricated End Face Seals. ASLE preprint 80-LC-1B-2, Aug. 1980.

4. Etsion, I.; and Dan, Y.: An Analysis of Mechanical Face Seal Vibrations. TME-359, Technion, Israel Institute of Technology, 1979.

5. Burton, R. A.: Discussion of paper by Etsion, I., Squeeze Effects in Radial Face Seals. ASME Paper 79-LUB-10, Oct. 1979.

6. Etsion, I.; and Burton, R. A.: Observation of Self-Excited Wobble in Face Seals. J. Lubr. Technol., vol. 101, no. 4, Oct. 1979, pp. $526-528$.

7. Metcalfe, R.: Dynamic Whirl in Well Aligned, Liquid Lubricated End Face Seals with Hydrostatic Tilt Instability. ASLE preprint 80 -LC1B-1, Aug. 1980 .

8. Etsion, I.: The Accuracy of the Narrow Seal Approximation in Analyzing Radial Face Seals. ASLE Trans., vol. 23, no. 2, Apr. 1980, pp. 208-216.

9. Etsion, I.: Nonaxisymmetric Incompressible Hydrostatic Pressure Effects in Radial Face Seals. J. Lubr. Technol., vol. 100, no. 3, July 1978, pp. 379-385.

10. Etsion, I.; and Sharoni, A.: Performance of End-Face Seals with Diametral Tilt and Coning -- Hydrostatic Effects. ASLE Trans., vol. 23, no. 3, July 1980 . 


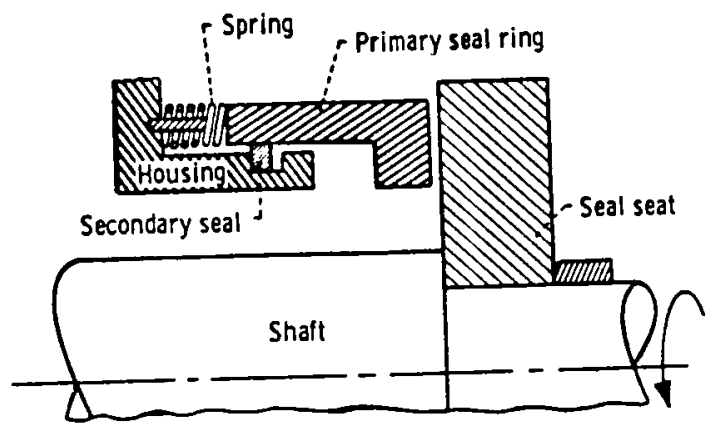

figure 1. - Schematic of a radial face seal.

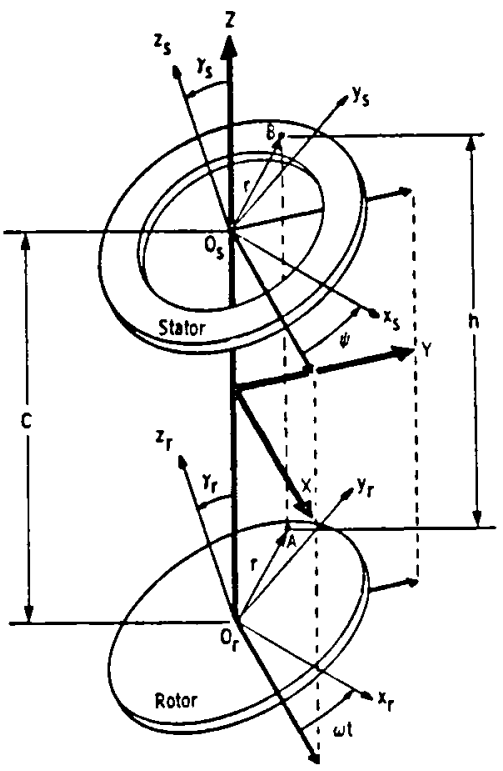

figure 2. Seal model and coordinate systems. 


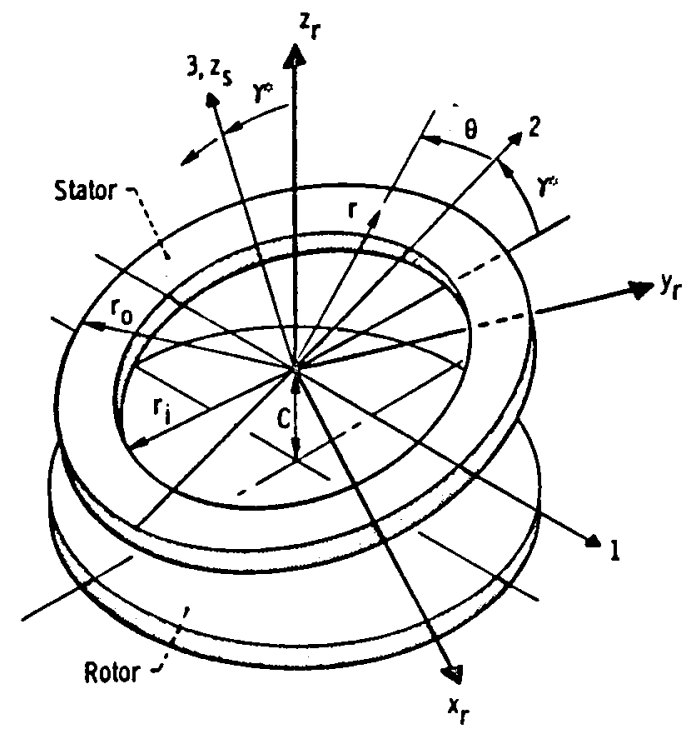

Figure 3. - Relative position between stator and rotor.

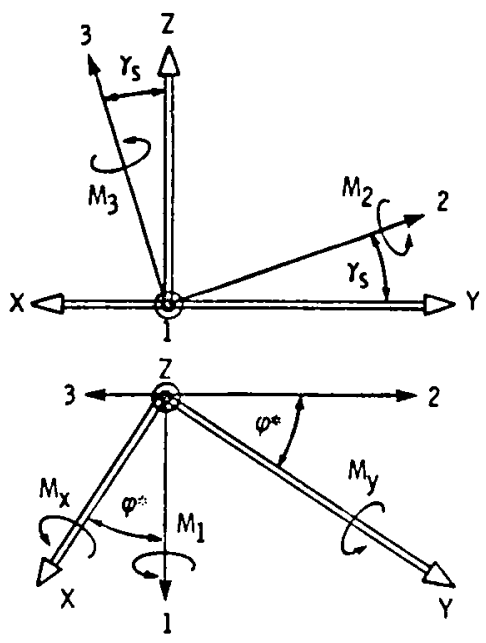

Figure 4. - Orientation of inertial system $X, Y, Z$ in rotating system $1,2,3$. 


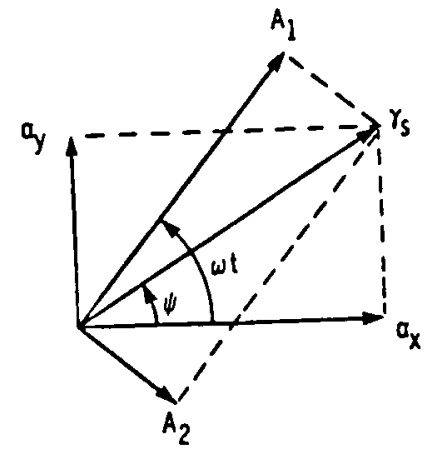

Figure 5. - Graphical representation of the particular solution for $a_{x}$ and $a_{y}$.

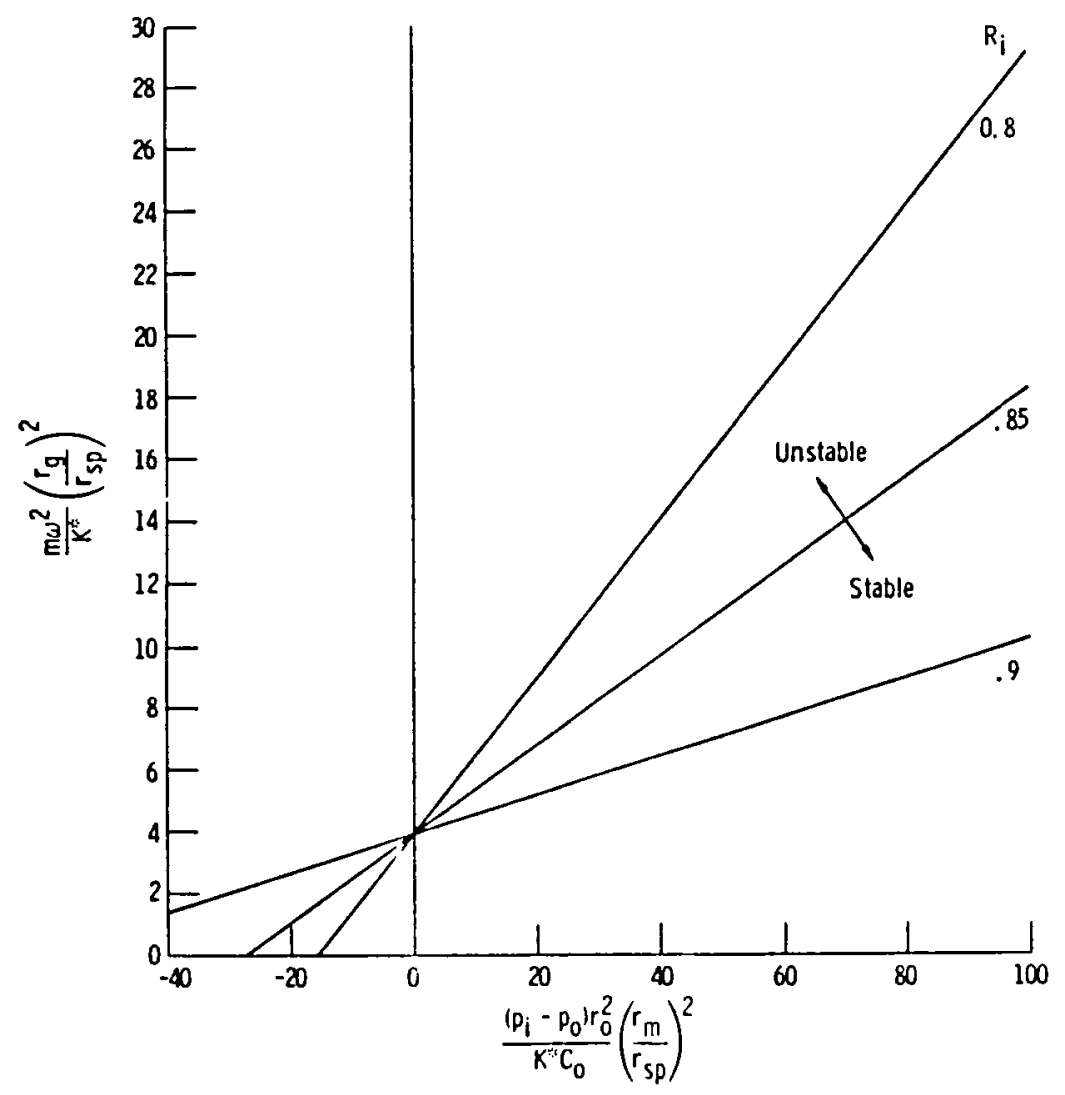

Figure 6. - Stability maps for the seal stator at various radius ratios $R_{i}$. 


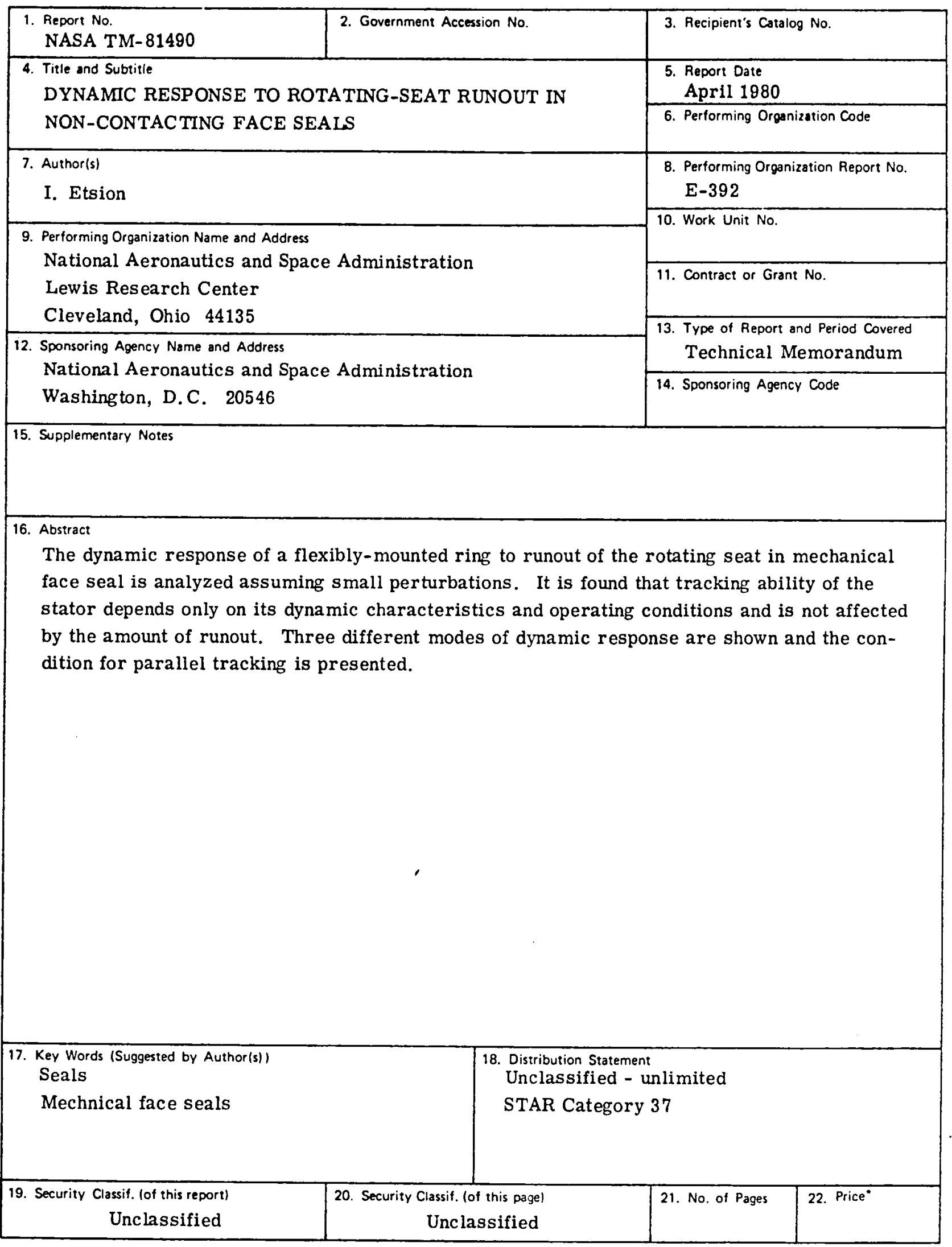

*For sale by the National Technical Information Service, Springfield. Virginia 22161 


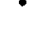


National Aeronautics and Space Administration BOOK

Washington, D.C.

20546

Official Business

Penalty for Private Use, $\$ 300$
Postage and Fees Paid

National Aeronautics and

Space Administration

NASA-451

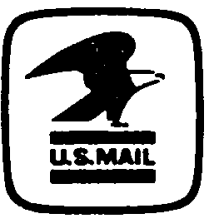

; 